\title{
Evaluation and Correlation of Beta Angle with Wits Appraisal and ANB Angle in Various Skeletal Malocclusion Groups-A Cephalometric Study
}

\author{
Mandeep K. Bhullar ${ }^{1}$ Arun K. Thakur ${ }^{2} \quad$ Sanjay Mittal ${ }^{1} \quad$ Isha Aggarwal ${ }^{1} \quad$ Tanzin Palkit $^{1} \quad$ Merry Goyal $^{1}$ \\ ${ }^{1}$ Department of Orthodontics, Bhojia Dental College and Hospital, \\ Baddi, Himachal Pradesh, India \\ Address for correspondence Arun K. Thakur, MBBS, Bhojia Dental \\ ${ }^{2}$ Department of Orthodontics, Bhojia Dental College and Hospital, \\ College and Hospital, Baddi, Himachal Pradesh, 173205, India \\ Baddi, Himachal Pradesh, India \\ (e-mail: thakurarun81@gmail.com).
}

Dent J Adv Stud 2021;9:96-100.

\begin{abstract}
Introduction Sagittal skeletal discrepancies are frequently assessed by Wits appraisal and point A-Nasion-point B (ANB) angle. These angular and linear measurements depend upon various factors and sometime produced inaccurate results. Beta angle has been introduced recently and possesses significant advantage over ANB and Wits appraisal, because it is independent of cranial landmarks and dental occlusion.

Aim To evaluate and correlate beta angle in various skeletal malocclusions and its correlation with Wits appraisal and ANB angle.

Material and Methods The present study was carried out in Bhojia Dental College and Hospital, Baddi, Himachal Pradesh, India. A total of 63 pretreatment lateral cephalograms (23 skeletal class I, 20 skeletal class II, and 20 skeletal class III) of patients aged between 14 to 25 years were included. Various landmarks and planes were identified and marked. Values of Wits appraisal, ANB angle, and beta angle were recorded. Comparisons of group were made with the chi-square test. Spearman correlation coefficient was calculated to see relation between different values.

Results Values of correlation coefficient of beta angle with Wits appraisal and ANB angle were -0.645 and -0.815 , respectively.

Keywords

- Beta angle

- ANB angle

- Wits appraisal

Conclusion Overall beta angle showed strong correlation with Wits appraisal and ANB angle, however correlation of beta angle with Wits appraisal and ANB angle among various skeletal malocclusion groups (skeletal class I, II, and III) was not statistically significant.
\end{abstract}

DOI https://doi.org/

$10.1055 / \mathrm{s}-0041-1731923$

ISSN 2321-1482
(C) 2021. Bhojia Dental College and Hospital affiliated to Himachal Pradesh University.

This is an open access article published by Thieme under the terms of the Creative Commons Attribution-NonDerivative-NonCommercial-License, permitting copying and reproduction so long as the original work is given appropriate credit. Contents may not be used for commercial purposes, or adapted, remixed, transformed or built upon. (https://creativecommons.org/licenses/by-nc-nd/4.0/).

Thieme Medical and Scientific Publishers Pvt. Ltd. A-12, 2nd Floor, Sector 2, Noida-201301 UP, India 


\section{Introduction}

Orthodontic diagnosis is an integral aspect of treatment planning in orthodontics. Sagittal assessment of skeletal jaw relationship is critical in accurate diagnosis. Edward $\mathrm{H}$. Anglein 1899 classify malocclusion into class I, class II, and class III categories, based upon the relation of mesiobuccal cusp of maxillary first molar to the buccal groove of mandibular first molar. ${ }^{1}$ Soon after, it was realized that this system of classification is not complete, as it does not include other important parameters. Emergence of cephalometry revolutionizes the field of orthodontic diagnosis. There are various important landmarks on lateral cephalogram with the help of which we can assess skeletal jaw relationship. ANB angle and Wits appraisal are commonly used indicators to determine the sagittal skeletal discrepancy. ${ }^{2,3}$ Measurement of ANB angle and Wits appraisal depend upon various factors and sometime produced inaccurate results. Beta angle introduced recently has significant advantage over ANB and Wits appraisal, because it is Independent of various landmarks of cranium and dental occlusion.

\section{Aim of Study}

To evaluate and correlate beta angle in various skeletal malocclusions and its correlation with Wits appraisal and ANB angle.

\section{Material and Methods}

The present study was carried out in Bhojia Dental College and Hospital, Baddi, Himachal Pradesh, India. A total of 63 pretreatment lateral cephalograms were taken and recorded in natural head position. Various landmarks were identified ( - Fig. 1) and marked. Values of ANB and beta angle (-Fig. 2) and Wits appraisal (-Fig. 3) were recorded. Using existing anteroposterior indicators of skeletal malocclusion

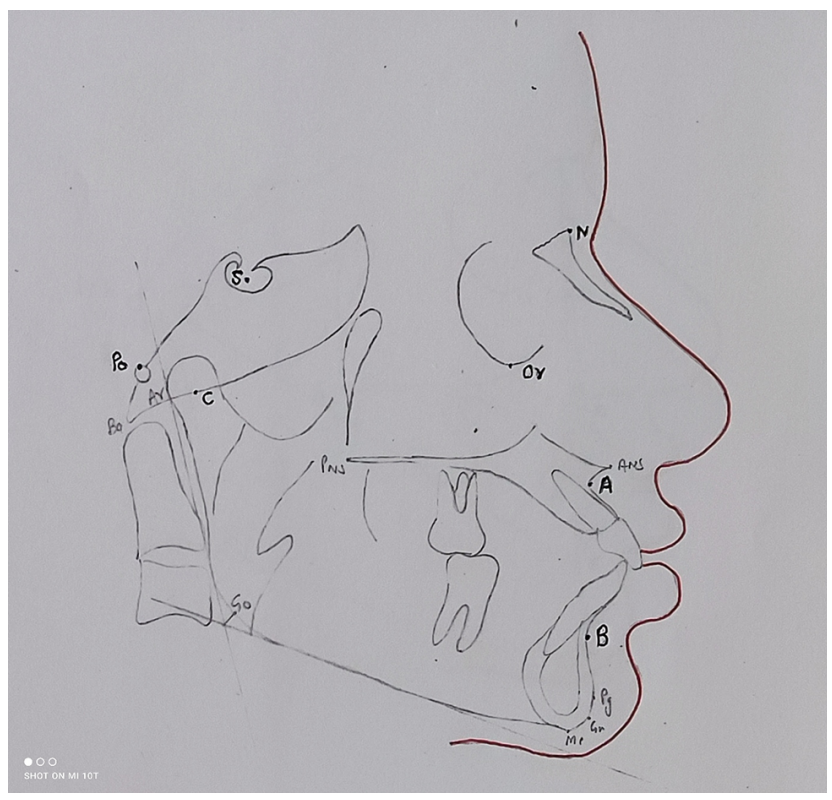

Fig. 1 Cephalometric landmarks considered in the study.

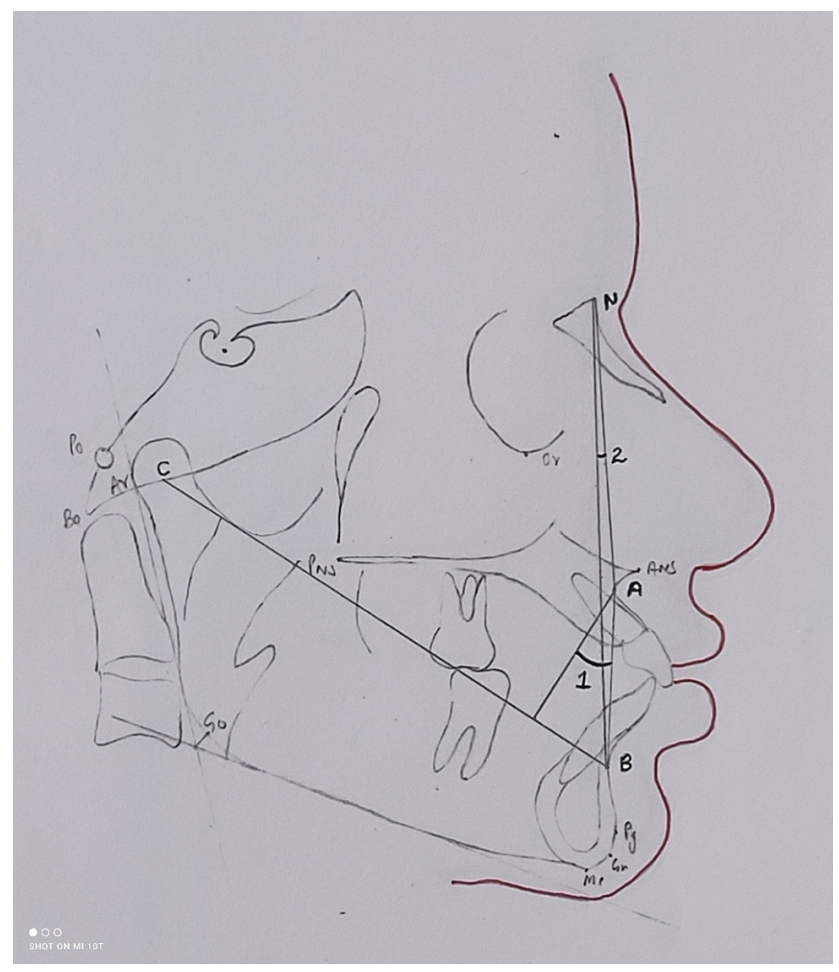

Fig. 2 Cephalometric angular measurements considered in study.

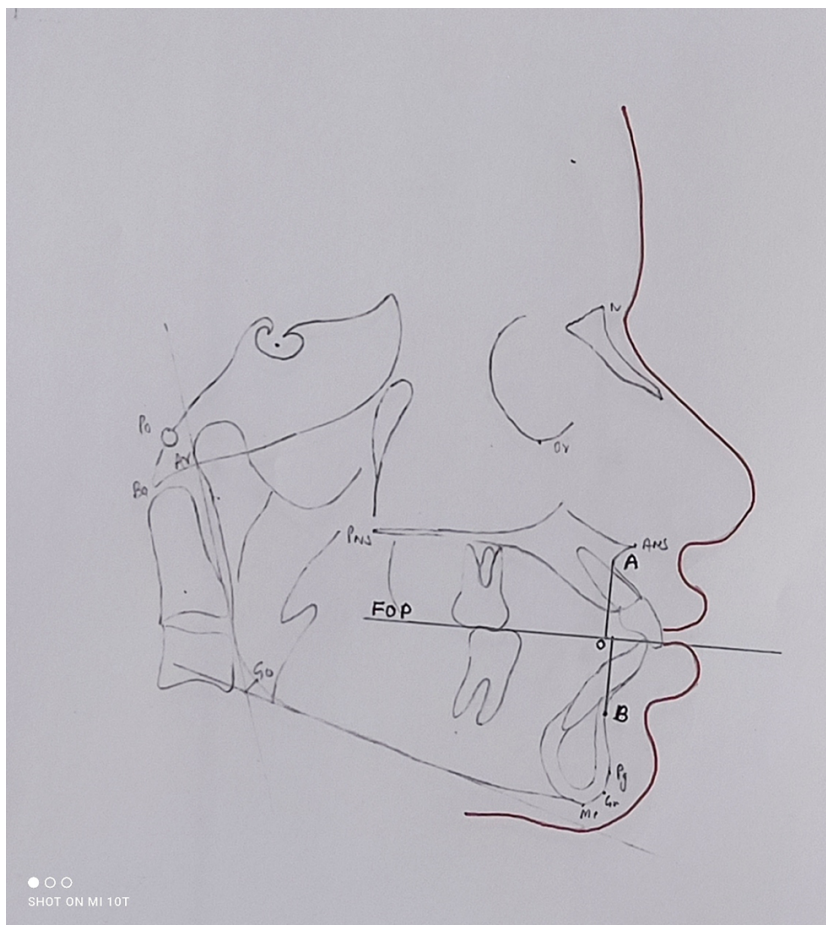

Fig. 3 Linear measurements considered in study.

(Wits appraisal, ANB and beta angle), these cases were distributed into three categories (23 skeletal class I, 20 skeletal class II, and 20 skeletal class III).

\section{Inclusion Criteria}

Those patients were included in the study who have attained permanent dentition stage and were of 14 to 25 years of age. 
Table 1 Descriptive statistics for ANB angle, Wits appraisal, and beta angle in skeletal class I, class II, and class III groups

\begin{tabular}{|c|c|c|c|c|c|c|c|c|c|}
\hline \multirow{2}{*}{\multicolumn{2}{|c|}{ Group }} & \multirow[t]{2}{*}{$\mathrm{N}$} & \multirow[t]{2}{*}{ Mean } & \multirow{2}{*}{$\begin{array}{l}\text { Std. } \\
\text { deviation }\end{array}$} & \multirow[t]{2}{*}{ Minimum } & \multirow[t]{2}{*}{ Maximum } & \multicolumn{3}{|c|}{ Percentiles } \\
\hline & & & & & & & 25th & $\begin{array}{l}\text { 50th } \\
\text { (median) }\end{array}$ & 75th \\
\hline \multirow{4}{*}{$\begin{array}{l}\text { Skeletal } \\
\text { class I }\end{array}$} & ANB (degree) & 23 & 2.48 & 1.238 & 0 & 5 & 2.00 & 3.00 & 3.00 \\
\hline & Witts appraisal & 23 & 0.7609 & 2.91497 & -8.00 & 5.50 & 0.0000 & 1.0000 & 2.0000 \\
\hline & Beta angle & 23 & 31.4348 & 4.38827 & 26.00 & 45.00 & 29.0000 & 31.0000 & 34.0000 \\
\hline & Group & 23 & 1.00 & .000 & 1 & 1 & 1.00 & 1.00 & 1.00 \\
\hline \multirow{4}{*}{$\begin{array}{l}\text { Skeletal } \\
\text { class II }\end{array}$} & ANB (degree) & 20 & 5.60 & 1.759 & 2 & 9 & 4.25 & 5.00 & 6.75 \\
\hline & Wits appraisal & 20 & 3.5100 & 3.89560 & -4.00 & 9.00 & 1.2500 & 3.7500 & 6.7500 \\
\hline & Beta angle & 20 & 23.8500 & 3.55816 & 16.00 & 29.00 & 21.2500 & 24.5000 & 26.7500 \\
\hline & Group & 20 & 2.00 & 0.000 & 2 & 2 & 2.00 & 2.00 & 2.00 \\
\hline \multirow{4}{*}{$\begin{array}{l}\text { Skeletal } \\
\text { class III }\end{array}$} & ANB (degree) & 20 & -1.97 & 1.674 & -7 & 0 & -2.38 & -2.00 & -1.00 \\
\hline & Witts appraisal & 20 & -3.8750 & 3.11986 & -8.00 & 2.00 & -6.5000 & -4.5000 & -1.0000 \\
\hline & Beta angle & 20 & 39.1000 & 3.86822 & 28.00 & 48.00 & 38.0000 & 39.0000 & 41.3750 \\
\hline & Group & 20 & 3.00 & .000 & 3 & 3 & 3.00 & 3.00 & 3.00 \\
\hline
\end{tabular}

Table 2 Overall correlation between beta angle, ANB, and Wits appraisal

\begin{tabular}{|c|c|c|c|c|c|}
\hline & & & ANB (degree) & Wits appraisal & Beta angle \\
\hline \multirow[t]{9}{*}{ Spearman's rho } & \multirow[t]{3}{*}{ ANB (degree) } & $\begin{array}{l}\text { Correlation } \\
\text { coefficient }\end{array}$ & 1.000 & $0.661^{\mathrm{a}}$ & $-0.815^{\mathrm{a}}$ \\
\hline & & Sig. (2-tailed) & $<0.001$ & 0.000 & 0.000 \\
\hline & & $n$ & 63 & 63 & 63 \\
\hline & \multirow[t]{3}{*}{ Wits appraisal } & $\begin{array}{l}\text { Correlation } \\
\text { coefficient }\end{array}$ & $0.661^{a}$ & 1.000 & $-0.645^{a}$ \\
\hline & & Sig. (2-tailed) & 0.000 & $<0.001$ & 0.000 \\
\hline & & $n$ & 63 & 63 & 63 \\
\hline & \multirow[t]{3}{*}{ Beta angle } & $\begin{array}{l}\text { Correlation } \\
\text { coefficient }\end{array}$ & $-0.815^{a}$ & $-0.645^{a}$ & 1.000 \\
\hline & & Sig. (2-tailed) & 0.000 & 0.000 & $<0.001$ \\
\hline & & $n$ & 63 & 63 & 63 \\
\hline
\end{tabular}

${ }^{a}$ Correlation is significant at the 0.01 level (2-tailed).

\section{Exclusion Criteria}

Patients who had previous orthodontic treatment or orthognathic surgery, craniofacial disorders, or congenital defects were excluded from the study.

\section{Cephalometric Landmarks (-Fig. 1)}

Following are the various cephalometric landmarks used in the study:

1. Sella, 2. porion, 3. center of condyle, 4. orbitale, 5. nasion, 6. point A, 7. point B.

\section{Cephalometric Angular Measurements (-Fig. 2)}

1. Beta angle: Angle formed between A-B line and the perpendicular line dropped from point $A$ on line connecting point $C$ and point $B$.
2. ANB: The angle from point $A$ to nasion and nasion to point B

\section{Cephalometric Planes and Linear Measurements (-Fig. 3)}

1. Functional occlusal plane: drawn through the region of overlapping cusps of maxillary first molar and bicuspids.

2. AO Line: perpendicular drawn from point $A$ on to the functional occlusal plane.

3. BO Line: perpendicular drawn from point B on to the functional occlusal plane.

4. AO-BO (mm): distance between $\mathrm{AO}$ and $\mathrm{BO}$.

\section{Statistical Analysis}

Analysis was carried out using IBM SPSS Statistics (version 22.0). Various measurements were recorded. Continuous data was given as mean \pm standard deviation 
BAngle with Wits Appraisal and ANB Angle in Skeletal Malocclusion Groups Bhullar et al. 99

Table 3 Correlation Between ANB angle, Wits appraisal, and beta angle in skeletal class I, class II, and class III groups

\begin{tabular}{|c|c|c|c|c|c|c|}
\hline \multicolumn{4}{|c|}{ Group } & \multirow{2}{*}{$\begin{array}{l}\text { ANB (degree) } \\
1.000\end{array}$} & \multirow{2}{*}{$\begin{array}{l}\begin{array}{l}\text { Wits } \\
\text { appraisal }\end{array} \\
0.203\end{array}$} & \multirow{2}{*}{$\begin{array}{l}\text { Beta angle } \\
-0.229\end{array}$} \\
\hline \multirow[t]{9}{*}{$\begin{array}{l}\text { Skeletal } \\
\text { class I }\end{array}$} & \multirow[t]{9}{*}{ Spearman's rho } & \multirow[t]{3}{*}{ ANB (degree) } & $\begin{array}{l}\text { Correlation } \\
\text { coefficient }\end{array}$ & & & \\
\hline & & & Sig. (2-tailed) & $<0.001$ & 0.354 & 0.292 \\
\hline & & & $n$ & 23 & 23 & 23 \\
\hline & & \multirow[t]{3}{*}{ Wits Appraisal } & $\begin{array}{l}\text { Correlation } \\
\text { coefficient }\end{array}$ & 0.203 & 1.000 & 0.041 \\
\hline & & & Sig. (2-tailed) & 0.354 & $<0.001$ & 0.854 \\
\hline & & & $n$ & 23 & 23 & 23 \\
\hline & & \multirow[t]{3}{*}{ Beta angle } & $\begin{array}{l}\text { Correlation } \\
\text { coefficient }\end{array}$ & -0.229 & 0.041 & 1.000 \\
\hline & & & Sig. (2-tailed) & 0.292 & 0.854 & $<0.001$ \\
\hline & & & $n$ & 23 & 23 & 23 \\
\hline \multirow[t]{9}{*}{$\begin{array}{l}\text { Skeletal } \\
\text { class II }\end{array}$} & \multirow[t]{9}{*}{ Spearman's rho } & \multirow[t]{3}{*}{ ANB (degree) } & $\begin{array}{l}\text { Correlation } \\
\text { coefficient }\end{array}$ & 1.000 & 0.062 & -0.002 \\
\hline & & & Sig. (2-tailed) & $<0.001$ & 0.794 & 0.992 \\
\hline & & & $n$ & 20 & 20 & 20 \\
\hline & & \multirow[t]{3}{*}{ Wits appraisal } & $\begin{array}{l}\text { Correlation } \\
\text { coefficient }\end{array}$ & 0.062 & 1.000 & -0.105 \\
\hline & & & Sig. (2-tailed) & 0.794 & $<0.001$ & 0.661 \\
\hline & & & $n$ & 20 & 20 & 20 \\
\hline & & \multirow[t]{3}{*}{ Beta angle } & $\begin{array}{l}\text { Correlation } \\
\text { coefficient }\end{array}$ & -0.002 & -0.105 & 1.000 \\
\hline & & & Sig. (2-tailed) & 0.992 & 0.661 & $<0.001$ \\
\hline & & & $n$ & 20 & 20 & 20 \\
\hline \multirow[t]{9}{*}{$\begin{array}{l}\text { Skeletal } \\
\text { class III }\end{array}$} & \multirow[t]{9}{*}{ Spearman's rho } & \multirow[t]{3}{*}{ ANB (degree) } & $\begin{array}{l}\text { Correlation } \\
\text { coefficient }\end{array}$ & 1.000 & 0.383 & -0.323 \\
\hline & & & Sig. (2-tailed) & $<0.001$ & 0.096 & 0.165 \\
\hline & & & $n$ & 20 & 20 & 20 \\
\hline & & \multirow[t]{3}{*}{ Wits appraisal } & $\begin{array}{l}\text { Correlation } \\
\text { coefficient }\end{array}$ & 0.383 & 1.000 & -0.318 \\
\hline & & & Sig. (2-tailed) & 0.096 & $<0.001$ & 0.171 \\
\hline & & & $n$ & 20 & 20 & 20 \\
\hline & & \multirow[t]{3}{*}{ Beta angle } & $\begin{array}{l}\text { Correlation } \\
\text { coefficient }\end{array}$ & -0.323 & -0.318 & 1.000 \\
\hline & & & Sig. (2-tailed) & 0.165 & 0.171 & $<0.001$ \\
\hline & & & $n$ & 20 & 20 & 20 \\
\hline
\end{tabular}

(SD); range or median and interquartile range, as appropriate. Normality of quantitative data were checked by measures of Kolmogorov-Smirnov tests of normality. For non-normally distributed data, comparison based on the basis of groups was made by Kruskal-Wallis test, followed by Mann-Whitney test. Group comparisons of values of age were made by ANOVA test. Gender was reported as counts and percentages. Group comparisons were made with the chi-square test.

Spearman correlation coefficient was calculated to see relation between different values. $p$-Value $\leq 0.05$ was considered significant.

\section{Results}

There were total 63 pretreatment lateral cephalogram taken, among which 23 were comprised of skeletal Class I, 20 were of skeletal Class II, and 20 of skeletal Class III patients. Beta angle, ANB angle, and Wits appraisal of all patients in each skeletal group were measured. The overall mean value for Beta angle was $31.43 \pm 4.34^{\circ}$ for skeletal Class I group, 23.85 $\pm 3.55^{\circ}$ for skeletal Class II group, and $39 \pm 3.86^{\circ}$ for skeletal Class III group (-Table 1). The mean value of ANB angle and Wits appraisal in each skeletal group was measured and shown in - Table 1. Overall correlation between Beta angle, 
ANB angle, and Wits appraisal was shown in - Table 2, and the correlation of these variables in different skeletal groups was shown in - Table 3.

\section{Discussion}

Evaluation of sagittal discrepancy in upper and lower jaw is important, as it is important to differentiate patients who need orthodontic treatment or orthognathic surgery or both. ANB and Wits appraisal are commonly used indicators for this purpose. Several studies has demonstrated that that ANB and Wits appraisal depend upon various factors, and a more reliable linear or angular measurement is needed to correctly diagnose the anteroposterior discrepancy. Baik and Ververidou devised a new angle with the help of point A, point B and center of condyle, named as beta angle, and used it to determine sagittal jaw relationship. ${ }^{4}$ In present study, the value of beta angle for skeletal class I group came to be $31.43 \pm 4.34^{\circ}, 23.85 \pm 3.55^{\circ}$ for skeletal class II group, and $39 \pm 3.86^{\circ}$ for skeletal class III group. These values were according to norms given for Caucasian populations by Baik et al. According to present study, the any value of beta angle less than $27^{\circ}$ indicated skeletal class II malocclusion, and any value greater than $35^{\circ}$ showed skeletal class III malocclusion. Singh et al also established values of beta angle for north Indian populations, and these values were in accordance with norms laid for Caucasians by Baik et al. ${ }^{5}$

Similarly, Prasad et al studied the norms of beta angle to assess anteroposterior discrepancy for Nellore district population. ${ }^{6}$ Statistically significant difference was observed for beta angle within the three skeletal patterns, and there were no differences noted among Caucasian norms and Nellore district population.

According to study conducted by Aparna et al, subjects can be classified into different skeletal patterns with the help of beta angle, and the correlation and regression analysis for the total sample suggested a highly significant relation between beta angle and ANB angle and between beta angle and Wits appraisal. Beta angle can be more reliable in assessing sagittal jaw discrepancies than Wits appraisal and ANB angle. ${ }^{7}$ Beta angle does not use functional plane and is not affected by jaw rotations. ${ }^{4}$ However, it uses point $A$ and point $B$, which can be remodeled by orthodontic treatment and growth (Richardson, 1982; Frank, 1983; Rushton et al, 1991). Beta angle predicting a class II or class III skeletal pattern is unable to determine which jaw is at fault. ${ }^{8}$

In the present study, beta angle established a negative linear correlation with ANB angle and Wits appraisal with $r$ values of -0.815 and -0.645 , respectively. All these values were statistically significant ( $p \leq 0.01$ ), indicating beta angle decreases with increase in Wits appraisal and ANB angle. However, statistically significant results were not obtained when correlation of beta angle with Wits appraisal and ANB angle were done among skeletal class I, skeletal class II, and skeletal class III groups.

Jajoo et al compared beta and ANB angles for evaluation of sagittal skeletal discrepancy and concluded that both ANB and beta angles indicated significant differences with different skeletal patterns. They found that both ANB and beta angle were similar in supportive diagnostic measurements to establish sagittal jaw relationship. ${ }^{9}$

\section{Conclusion}

Overall, beta angle showed strong correlation with Wits appraisal and ANB angle, however the correlation of beta angle with Wits appraisal and ANB angle among skeletal class I, skeletal class II, and skeletal class III groups was not statistically significant.

\section{Conflict of Interest}

None declared.

\section{References}

1 Angle EH. Classification of malocclusion. Dent Cosmos 1899;41:248-264

2 Steiner CC. Cephalometrics for you and me. Am J Orthod 1953;39:729-755

3 Jacobson A. The "Wits" appraisal of jaw disharmony. Am J Orthod 1975;67(2):125-138

4 Baik CY, Ververidou M. A new approach of assessing sagittal discrepancies: the Beta angle. Am J Orthod Dentofacial Orthop 2004;126(1):100-105

5 Singh C, Kumar H, Verulkar A, Joshi R, Garg H. Norms for antero-posterior assessment of jaw relationship for north Indian population. Ind J O Dent Sci 2014;2(6)

6 Prasad M, Reddy KP, Talapaneni AK. Chaitanya N, Bhaskar Reddy MV, Patil R. Establishment of norms of the beta angle to assess the sagittal discrepancy for Nellore district population. J Nat Sci Biol Med 2013;4(2):409-413

7 Aparna P, Kumar DN, Prasad M, et al. Comparative assessment of sagittal skeletal discrepancy: a cephalometric study. J Clin Diagn Res 2015;9(4):ZC38-ZC41

8 Ali SM, Manjunath G, Sheetal A. A comparison of 3 new cephalometric angles with ANB and Wits appraisal for assessing sagittal jaw relationship. Int J Oral Care Res 2018;6(2):S28-S32

9 Jajoo A, Agarkar SS, Sharma S, Gadhiya N, Sonawane S, Narkhede S. Comparison of beta and ANB angles for evaluation of sagittal skeletal discrepancy: a cephalometric study. J Contemp Dent Pract 2018;19(6):739-742 